\title{
Una representación del fracaso en La Pérdida de Laura de Martín Kohan : el fiasco del diálogo entre cultura de masas y cultura letrada
}

\section{Cécile Ramirez}

\section{(2) OpenEdition Journals \\ Edición electrónica \\ URL: https://journals.openedition.org/cher/12388 \\ DOI: $10.4000 /$ cher. 12388 \\ ISSN: 2803-5992 \\ Editor \\ Presses universitaires de Strasbourg}

\section{Edición impresa}

Fecha de publicación: 30 junio 2012

Paginación: 191-201

ISBN: 978-2-35410-046-9

ISSN: 1968-035X

\section{Referencia electrónica}

Cécile Ramirez, «Una representación del fracaso en La Pérdida de Laura de Martín Kohan : el fiasco del diálogo entre cultura de masas y cultura letrada», reCHERches [En línea], 8 | 2012, Publicado el 21 febrero 2022, consultado el 23 febrero 2022. URL: http://journals.openedition.org/cher/12388 ; DOI: https://doi.org/10.4000/cher.12388

\section{c) (i) (2) (2)}

Ce(tte) œuvre est mise à disposition selon les termes de la Licence Creative Commons Attribution -

Pas d'Utilisation Commerciale - Partage dans les Mêmes Conditions 4.0 International. 


\title{
Una representación del fracaso en La Pérdida de Laura de Martín Kohan: el fiasco del diálogo entre cultura de masas y cultura letrada
}

\author{
Cécille Ramirez \\ Université Stendhal Grenoble III
}

\begin{abstract}
Con La pérdida de Laura, publicada en 1993, la obra de Martín Kohan (Buenos Aires, 1967) nace bajo el signo de la dicotomía y del fracaso de la comunicación. En una gran parte de su obra ficcional, en efecto, se pone en escena un encuentro (o más bien desencuentro) entre dos universos antagónicos que nunca logran entenderse del todo. La mayoría de las veces, esos dos universos corresponden, bajo formas variadas en la obra del escritor argentino, al de la cultura de masas frente al de la cultura letrada, en una binaridad casi obsesiva. La pérdida de Laura es probablemente la novela de Kohan que expresa de manera más tajante y brutal el fiasco del encuentro entre aquellos dos mundos. La ficción, en efecto, no sólo va revelando momentos muy claramente representativos de la incomunicabilidad, sino que también plantea desde el principio mismo de la novela unas condiciones que llevan en sí una comunicación en peligro, un lenguaje amenazado a muerte. La historia de la lucha fratricida entre Raúl y Miguel va configurando varios niveles de significaciones posibles; incita en todos casos a reflexionar acerca de ese aparente fracaso de la letra/literatura, pero también acerca de la imagen de una sociedad argentina cuyo carácter doble no pareciera tener resolución.
\end{abstract}




\section{Una comunicación laboriosa entre dos hermanos}

La novela se estructura en breves capítulos que alternan entre tres narradores en primera persona: Raúl, el hermano mayor, Miguel, el menor, y Laura, la novia de Raúl. Cada uno cuenta con su punto de vista su vivencia de la historia, que al principio parece ser la de su vida cotidiana, pero que pronto muestra una clara evolución hacia una intensificación del conflicto entre los hermanos, que desembocará en un final trágico. En efecto, el diálogo cotidiano entre Raúl y Miguel se vuelve pronto lucha frontal, principalmente porque el mayor quiere imponer por la fuerza su concepción de la vida. La narradora Laura, por su parte, enfoca su relato sobre su abuelo, que acaba de enviudar y le cuenta historias de su pasado antes de suicidarse. La narración que mayoritariamente transmite en estilo directo las palabras del abuelo está entrecortada por momentos en que Laura está con Raúl, o con los dos hermanos, o con Miguel; ella oscilla entre los dos y termina enamorándose del menor. En la madrugada que sigue su encuentro amoroso y sexual, Laura es asesinada por accidente por un amigo de Raúl, que se ha ido imaginando que Miguel tiene algo que ver en el episodio de las manos de Perón, cortadas y robadas en 1987. Miguel, traumatizado, termina en una cama de lo que parece ser un hospital psiquiátrico, y así termina la novela.

Lo que está en juego no es simplemente una lucha fratricida: es el enfrentamiento entre dos universos, ya que ambos hermanos representan una esfera bien definida, configurando - sin escapar de los estereotipos, a veces - un sistema binario que nunca se altera. Por su parte, Raúl es un representante puro de la cultura de masas: se dedica a un trabajo manual, ya que trabaja en una panadería heredada de su padre, donde se especializa en «masas»; divide su tiempo entre aquel trabajo, los encuentros en el bar con sus amigos en el que juegan a las cartas, los paseos por la calle con un amigo que siempre le habla de sus encuentros sexuales y de los pechos de las mujeres, y lo más importante de todo, los momentos dedicados a la televisión, y en particular al programa del Negro Olmedo, humorista muy popular en el tiempo en que transcurre la historia, los años ochenta. Miguel, por lo contrario, es estudiante de letras, y en la mayor parte de la novela se dedica a estudiar; desde pequeño siempre se ha negado a mirar la televisión, los gritos que dominaban la transmisión de los partidos de fútbol siempre lo hacían llorar. Sus paseos por las calles de Buenos Aires, los comparte, por su parte, con un amigo canadiense de visita por el país que investiga sobre Borges y Bioy Casares. 
Los hermanos no podían ser más antagónicos, y su convivencia implica una tensión constante. Por consiguiente, no es sorprendente para el lector ser testigo de situaciones de comunicación fracasada, entre las cuales queremos destacar las tres más significativas, como momentos clave en la novela. La primera ocupa todo el cuarto capítulo, en el que Miguel le recita sus declinaciones de latín a Raúl. Éste no deja de mirar televisión mientras lo interroga. El diálogo, relatado en estilo directo por el narrador Miguel, está entrecortado por las descripciones visuales del zapping al que se dedica el hermano, que interviene como un parásito en el diálogo. Raúl apenas lo escucha, y lo apura porque está por empezar el programa del Negro Olmedo. La voz de Miguel tiene que luchar no sólo contra los decibelios de la tele («Mi hermano se fastidió un poco, se enderezó en el sillón, subió otro poco el volumen del televisor», 19) sino también contra las imágenes que absorben la atención del hermano: Miguel le dice «Tendrías que ver si se dice pueya, así, con la i griega», pero esta interpelación cae en la nada: «Raúl no comprendió de inmediato y cambió dos veces de canal; en el tercer salto, se encontró con un dinosaurio que bramaba herido y eso le llamó la atención» (19). Notamos la ironía de la situación en que el latín está condenado a someterse frente a un objeto doblemente debilitado: herido en la ficción televisiva, desaparecido de la realidad desde hace millones de años.

El diálogo se rompe entonces cuando llega la hora del programa de Olmedo, y se disuelve en un murmullo de insulto por parte de Raúl, mientras Miguel escapa del ritual dejando la sala: «No voy a ver eso - le contesté yo, y me fui para la cocina para darle a entender que no discutiría el tema, y para ocuparme de la cena. - Andá a cagar, llegué a escuchar que murmuraba». Así, llega un punto en que la comunicación se hace imposible, y fracasa. En el décimo capítulo tiene lugar una segunda conversación larga, que transcurre en el bar en que suelen encontrarse Raúl y sus amigos. Ven pasar a Miguel por la ventana, lo llaman y lo obligan a quedarse con ellos. La conversación se enfoca pronto en figuras míticas, objetos de orgullo nacional que el clan de Raúl venera, y cuyas fotos adornan la pared del bar: Carlos Gardel, Leguisamo (jockey famoso), Di Stéfano (futbolista). Miguel desmonta el sistema mítico, aludiendo en particular al posible nacimiento en suelo francés de Carlos Gardel, lo cual deja al grupo de Raúl perplejo («desencajado») en un primer momento; luego, se niegan a aceptar la realidad y deciden cambiar de tema: «- Francés - se queda murmurando el Negro -, lo único que faltaba» (60). 
Después el diálogo deriva hacia lo que van a pedir al mozo. Miguel quiere Fanta pero lo obligan a tomar vino, y lo emborrachan. El proceso se acompaña de una serie de brindis exaltados e inquietantes del Negro Medina, el jefe del clan, en un torbellino que aniquila toda comunicación; se brinda sin distinción por Gardel, Perón, Maradona, las Islas Malvinas, el Mono Gatica, Leopoldo Marechal, actores y futbolistas, animadores de la tele, etc. Al final, Miguel está tan borracho que no puede ni caminar, ni hablar: observamos ahí el segundo fracaso efectivo de la comunicación. El capítulo 16 tiene como escenario la casa de los hermanos: Miguel narra la llegada de los amigos de Raúl, con cajas de pizzas y vino. El diálogo ahí es más breve, consiste en la insistencia para que Miguel se quede a mirar el programa de Olmedo con ellos, a la que se opone la resistencia cortés de aquél. Lo atan a una silla para obligarle a mirar, y uno de ellos está encargado de darle patadas en los tobillos si se le ocurre cerrar los ojos. Las imágenes desfilan y su descripción invade por completo la narración: ya no hay lugar para réplica alguna de los personajes. La comunicación, como podemos observarlo, fracasa cada vez: se extingue frente a la omnipotencia de la tele (primera situación), se disuelve en el alcohol (segunda situación), y de nuevo queda aplastada por la tele. En los tres casos fracasa porque se excluye, y cada vez más violentamente, a uno de los dialogantes. Los murmullos, por otra parte, aparecen aquí como una mímesis de una palabra que muere.

\section{El fracaso de la comunicación: del síntoma a la prueba última del fiasco}

Observamos primero un síntoma, en el íncipit a cargo de la narradora Laura, que introduce desde ya un elemento proléptico: la asociación entre el lenguaje y la muerte, síntoma de una comunicación incapaz de llevarse a cabo. Dicha asociación se expresa a través de una escena inaugural en la que la familia de la muchacha está reunida en un muelle para arrojar las cenizas de la abuela en el Río de la Plata. El capítulo entero se articula alrededor de una tensión entre lo que está arriba y lo que está debajo de la superficie. El motivo, en efecto, introduce y cierra la escena del muelle. Empieza así la novela: «Yo no sé, nunca supe, nunca te pregunté tampoco (en el fondo o en la superficie, no importa demasiado), si alguna vez estuviste en el muelle de los pescadores, en la costanera, en Buenos Aires» (7). Notamos los términos «fondo» $\mathrm{y}$ «superficie», que van a reaparecer varias veces, hasta esta ocurrencia que cierra la escena:

[Mi abuelo] meneó rápidamente la cabeza y lanzó la caja al río: primero la tapa (la placa de metal en la que se leía el nombre de mi abuela brilló por un 
momento con el reflejo del sol de la mañana) que cayó de canto y pronto se esfumó bajo la superficie, y luego la caja propiamente dicha, que cayó sobre el río con la concavidad hacia arriba, de modo que quedó flotando sobre el agua y siguió, y acaso siga aún, en una deriva inútil (9).

El detalle que quisiéramos poner de relieve es aquello que cae en el fondo: es el significante, la letra, asociados entonces con lo profundo, y que por otra parte se destacan positivamente no sólo por su brillo, sino por el empleo, por contraste, del adjetivo despectivo «inútil» asociado a lo que está sobre la superficie. Lo profundo del río también simboliza la muerte: «Ella -la ceniza o la lluvia, no sé, qué sé yo, o mi abuela, todavía mi abuela, quién sabe- fue poco a poco depositándose en la superficie del agua, y comenzó luego a hundirse, a asimilarse con lentitud al agua agitada». La imagen de la muerte como disolución en el agua, que se inscribe en continuidad con una tradición poética analizada por Gaston Bachelard en su obra L'eau et les rêves, es límpida. Citamos al ensayista:

... dans sa profondeur, l'être humain a le destin de l'eau qui coule. L'eau est vraiment l'élément transitoire. Il est la métamorphose ontologique essentielle entre le feu et la terre. L'être voué à l'eau est un être en vertige. Il meurt à chaque minute, sans cesse quelque chose de sa substance s'écoule. [...] L'eau coule toujours, l'eau tombe toujours, elle finit toujours dans sa mort horizontale (Bachelard 2010: 13).

El «ser» que cae en el agua es aquí la palabra, y la asociación se verá reforzada después, cuando el abuelo anuncie de manera metafórica su suicidio, al referirse, entre otras figuras, a las de Virginia Woolf y de Alfonsina Storni, ambas escritoras que buscaron la muerte en el agua. La novela queda profundamente marcada, entonces, por la asociación entre esos tres elementos: la profundidad, la letra y la muerte. En eso, tendríamos un elemento anunciador del fracaso del lenguaje y por ende de la comunicación.

Pero volvamos a los protagonistas de ésta, y a la definición de lo que es la comunicación según la Real Academia: una «transmisión de señales mediante un código común al emisor y al receptor». El problema, justamente, es que los hermanos no tienen un código común, pues entienden la vida e interpretan la realidad a partir de valores y de conceptos sumamente opuestos. Pronto el lector se da cuenta de que de todos modos, el diálogo estaba condenado a fracasar desde el principio, ya que es como si hablaran una lengua distinta. El sistema binario configurado por Miguel y Raúl, cada uno con su clan, es muy denso y necesitaría numerosas páginas para ser descrito de manera exhaustiva. Nos conformaremos por consiguiente 
con desarrollar tres antagonismos que simbolizan lo más eficientemente esas maneras tan incompatibles de experimentar la realidad. La primera dicotomía que constituye una traba para el diálogo es la que podríamos llamar "palabra versus imagen». En efecto, por una parte, la manera de vivir de Raúl parece ser dominada por el sentido de la vista, la importancia de la imagen; incluso se podría decir que su interpretación de las cosas está regida por la imagen. Tres ejemplos:

- sus criterios de evaluación de las mujeres son puramente físicos; dentro de esos criterios existe una jerarquía: lo primero son los pechos («tengo un póster de Luisa Albinoni. Tetas respetables, también», 72); lo segundo vendría a ser las nalgas ( $\mathrm{Y}$ a la Brodsky, que es otra destetada, pero que tiene un culo que no te lo podés olvidar una vez que lo conociste», 75).

- su vida es regida por la tele: las imágenes que desfilan ritman su cotidiano.

- las figuras a las que admira son las de los pósters: las chicas de las revistas pornográficas, los mitos de la nación fijados en los carteles (Perón, Evita, Maradona, Gardel).

La vida de Miguel, por lo contrario, es regida por el lenguaje. Si tomamos punto por punto las características propias a Raúl, todos los elementos toman la dirección opuesta:

- su hermano le presta una revista pornográfica, cuyas imágenes no despiertan mucho interés en él; en cambio, la utiliza como referencia bibliográfica para una monografía que está redactando en el mismo momento.

- sus actividades están todas asociadas a las letras, de una manera o de otra: la lección de latín, la monografía, las largas conversaciones sobre literatura con Brad, el amigo canadiense.

- las figuras a las que admira no son las de los pósters: el ejemplo más significativo surge en una conversación entre Miguel y Brad sobre Bioy Casares y Borges, en la que el canadiense observa la influencia de éste sobre aquél, aludiendo a Bustos Domecq como un «monstruo de dos cabezas» (83). Si bien Borges en los años ochenta ya fue petrificado por la mitificación, los estudiantes de letras que son los dos personajes se inscriben en contradicción con el monolitismo propio de la postura mitificadora: su comentario sugiere en efecto la imagen de una fusión que confundiría un poco los dos rostros. Estamos por lo tanto mucho más allá de la imagen concreta de los pósters de Raúl. Nos situamos aquí en lo abstracto, que surge únicamente gracias a las palabras. 
Por contraste, Raúl da pruebas de un lenguaje pobre: hablando de su hermano, dice: «Es un tipo raro, raro. No digo puto ¿eh? Digo raro, medio extraño. Raro, difícil de entender» (38). Y cuando su amigo el Negro Medina le pregunta qué estudia Miguel: «Letras - le contesto, y él se me queda mirando -. Cuentos, poesías... esas cosas».

La manera de interpretar la vida de los dos hermanos es también completamente opuesta a nivel de la experiencia temporal. No sólo como personaje, sino también como narrador, Raúl muestra que lo suyo es la inmediatez, lo instantáneo: el zapping que ocupa cada uno de sus días es el reino de lo instantáneo. Su postura en tanto narrador va confirmando tal impresión, a través de su tendencia a la transcripción en estilo directo de los diálogos, que corresponde en términos de Gérard Genette a la ecuación Tiempo del relato $=$ Tiempo de la historia. Por lo contrario, Miguel como narrador no sólo se dedica mucho más a las pausas descriptivas (Tiempo del relato $=\mathrm{n}$, Tiempo de la historia $=0$ ), sino que maneja con facilidad el sumario («sommaire» de Genette, Tiempo del relato < Tiempo de la historia), posturas que revelan una clara tendencia a la puesta en perspectiva temporal. Lo suyo es la duración, la paciencia, la perseverancia en el trabajo. Siendo la noción del tiempo un elemento determinante para la concepción de la realidad propia a cada individuo, podemos deducir que Miguel y Raúl tienen una imagen totalmente diferente de esa realidad.

La tercera dicotomía, que se inscribe en continuidad con las dos anteriores o incluso puede verse como algo que deriva de ambas, es la pareja «pluralidad de sentidos versus monolitismo». El lector va descubriendo que Raúl y sus amigos están fuertemente marcados por la atracción y hasta por la necesidad de la univocidad, de la homogeneidad, y que no cesan de reivindicar unas verdades límpidas que consideran inquebrantables. Se manifiesta por ejemplo en la recurrencia, tanto en el discurso narrativo de Raúl como en las conversaciones, de los adverbios «siempre»y «nunca». Se puede ver ahí la obsesión de una continuidad que tranquiliza. Todo queda simplificado. Los adjetivos «todos», «todas» y el pronombre neutro «todo» confirman el aspecto perentorio de algunas afirmaciones. Ser «igual que todo el mundo» es una cualidad valorada: «Va a tener que ver la televisión lo mismo. Porque esa es la cultura de la gente, porque todo el mundo mira la televisión». Pensamos también en el momento ya citado, en que Raúl y los amigos no soportan que Gardel pueda tener una nacionalidad doble: tiene que ser argentino, y punto. Miguel, por lo contrario, no se deja seducir por esa coherencia forzada y artificial contenida en los mitos de la nación. Vive en una actitud constante 
de cuestionamiento, en todos los niveles (analiza por ejemplo su propio comportamiento hacia su hermano, siempre preocupado por tratar de ser justo con él). Es el rey del matiz, de la diferenciación entre varios niveles, como si con aquella actitud buscara ser más fiel a la complejidad de la vida: «la reacción de Raúl tuvo dos aspectos: uno, explícito; el otro, tácito», para citar una de las numerosísimas manifestaciones de tal postura. Asistimos entonces a un enfrentamiento entre una visión unívoca y una visión plural del mundo, lo cual es otro impedimento fuerte para que las dos esferas se entiendan a la hora de comunicar.

El diálogo quedaba por ende condenado desde el principio al fracaso, y son dos las pruebas últimas de éste: en un nivel literal, el final de la novela corresponde a la tiranía de las masas triunfando sobre la esfera letrada, ya que se aniquila para siempre a uno de los dialogantes. Miguel, tan sedado que ya no puede hablar, tiene la mente en blanco. Última ironía: le instalan un televisor, "grande y a colores »: «El televisor está andando cuando me lo traen. Lo dejan tan cerca, tan cerca de mí, que ya no hay forma de ver la pared blanca que yo sé que está detrás». Ese «ya andando», que da la impresión de que va a andar hasta un tiempo infinito, sumado a la ocupación de todo el espacio de la pared, da a entender lo aplastante, lo fatal de aquella presencia. Lo confirma la invasión de las secuencias cortas, que revelan una mezcla sin sentido de telenovelas, programas culinares y noticieros, en los cuales se llega a entender el asesinato de Laura y el suicidio de su abuelo. Ésta es la segunda manifestación, más metafórica, del fracaso del diálogo: muere Laura, la que tenía una posición intermedia, la que establecía un puente entre los dos hermanos y entre los dos mundos antagónicos. Como vimos antes, la escena inaugural la colocaba en un lugar intermedio entre la vida y la muerte, entre el elemento terrenal y el acuático, entre la superficie (que podría simbolizar el mundo superficial de Raúl) y lo profundo (el mundo de las palabras, el de Miguel). Aniquilado el puente entre los dos mundos, se consuma para siempre el fracaso de la comunicación.

\section{¿Asumir el fracaso como parte de la argentinidad?}

Ahora bien, tras entender esas modalidades del fracaso, que es parte de un sistema coherente construido por la novela, conviene preguntarse qué habrá detrás de tal fiasco, ya que es un motivo recurrente en la obra del escritor. El antagonismo y la incomunicabilidad son omnipresentes, en efecto, en las ficciones de Martín Kohan. El informe. San Martín y el otro cruce de los Andes plantea una relación epistolar entre un historiador 
pomposo y un hombre al que contrató para darle detalles historiográficos a los que él no puede acceder, viviendo en Mendoza. La novela cuenta la historia de una incomprensión total entre los dos hombres, ya que el segundo se empeña en desviar la Historia hacia una historia de amor de lo más cursi. Segundos afuera por su parte pone en escena, sobre un trasfondo policial, diálogos entre un periodista cultural, culto y melómano, y un periodista deportivo, adepto de la cultura de masas; tampoco ahí logran entenderse. Cuentas pendientes, la última novela, desarrolla una relación conflictiva entre un hombre simple y el dueño de su departamento, escritor y doble de Kohan, al que no quiere pagar. El interés novelístico del motivo del conflicto podría ser una primera hipótesis de la razón de tal leitmotiv: se lo puede considerar como un motor de la escritura, propicio a diferentes juegos sobre las nociones de paradoja, de doble; puede favorecer estructuras complejas que se valen de paralelismos; es también un recurso que llama a la crueldad o al humor (el lector se puede sentir muy incómodo, también se puede reír mucho con Kohan).

Sin embargo, podría haber conflicto y luego reconciliación; no la hay, puesto que el antagonismo nunca se resuelve. En cierto modo, la fuente de ese trabajo constante con el motivo de la incomunicabilidad, la explica el autor mismo cuando dice, en una entrevista sobre su novela Segundos afuera:

Estoy bastante agotado del mecanismo sistemático de la matización. En épocas muy crispadas con debates y posiciones muy radicalizadas, matizar y atenuar puede ser necesario, pero en una época tan lavada, sin posiciones fuertes, sin perspectivas más o menos definidas, donde todo ya está matizado, agregar más atenuaciones me cansa. Prefiero recuperar las antinomias (Kohan 2005).

El fracaso del diálogo sería una manera de llevar hasta sus extremidades lo que es el antagonismo. Podemos deducir de esas palabras que más vale un fracaso de la comunicación que una falsa comunicación en la que todo el mundo pretendería estar de acuerdo. De hecho, podemos decir incluso que hay cierto horror contenido en la noción de consenso y de reconciliación, si pensamos en las leyes de Punto Final y de Obediencia debida de 1986 y 1987, que llamaron a una reconciliación nacional que no podía dejar de ser enfermiza en lo que implicaba, y que probablemente debe haber marcado al joven escritor en esos años.

Tras considerar los posibles orígenes del tema del fracaso como un motivo privilegiado en el mundo ficcional de la obra de Kohan, tratemos 
de dar hipótesis acerca de sus significados, lo que el autor llama «las capas de lectura posibles». Los hermanos Raúl y Miguel, para volver a ellos, pero también en muchos aspectos las parejas de personajes a las que hemos aludido, parecen ser representantes de una Argentina doble, cuyas dos caras serían imposibles de conciliar. Habría una Argentina mítica, deseada (la de Raúl, la de los mitos de la nación que conforman una unidad nacional, porque todos los argentinos se reconocen en ellos, se identifican con ellos) y una Argentina real (la que expresa Miguel en un lenguaje fiel a la complejidad de lo real, la que por otra parte está amenazada por el fracaso): una aspiración a la grandeza históricamente muy presente en el país, una desilusión tanto más rotunda. María Cristina Pons explica muy bien ese fuerte contraste entre el deseo y la realidad, en su introducción al ensayo Delirios de grandeza. Los mitos argentinos: memoria, identidad, cultura:

... un complejo mítico que habla de un país fundado en la fisura, polarizado desde sus orígenes, y que no ha llegado a articular una idea unitaria de qué tipo de nación se quiere construir o qué entendemos por nación. [...] Se llegó a pensar, incluso, que somos el ejemplo de oportunidades perdidas. Sea cierto o no, en nuestros delirios de grandeza aspiramos a todo, pero [...] a nosotros ya nos bombardearon, tenemos nuestros desaparecidos, nos quitaron toda la plata y volvimos a ser el trasero del mundo [...]. El mito aparece llenando el vacío de una visión dicotómica, o curando las heridas de un país fundado en la fisura de una polarización irreductible, y con un destino de grandeza al que no se resigna a abandonar. (Pons 2005: 20-21; 34)

La sociedad argentina fracasaría entonces en sus esfuerzos para definirse una identidad propia. Ahora bien, sería muy tentador decir que la literatura, por su lado, no fracasa, que en cierto modo compensa en gran medida el fracaso puesto en escena. Kohan no parece estar de acuerdo con esa idea, por lo menos no considera la literatura como el héroe que nos salvaría del fiasco. Dice en un artículo: «Para mí un escritor de veras es el que entiende hasta qué punto la literatura se relaciona siempre con el fracaso y transcurre siempre en lo desapercibido, incluso, o sobre todo, cuando tiene "éxito" o cuando gana "notoriedad"» (Kohan 2009). De hecho, opina a menudo en las entrevistas, la literatura no tiene un lugar social suficiente como para tener influencia alguna. Esa asociación entre la literatura y el fracaso es un tanto enigmática, y difícil de aceptar para un lector de la obra de Kohan, que no puede dejar de sentir una energía vital corriendo por las líneas, difícilmente compatible con lo fracasado. Lo que sí podríamos concerderle sería la imagen de un fracaso, pero un fracaso fecundo, asumido, casi placentero. En eso Kohan parece lograr lo que no logran sus personajes: integrar dos facetas 
que parecen incompatibles en primera instancia: el fracaso, y la aceptación jovial del fracaso. Aquella aceptación podría ser, por consiguiente, un logro posible en la definición de la argentinidad. Un análisis de la figura mítica de Maradona por Kohan tiende a confirmar tal hipótesis:

Maradona que es, como nadie ignora, un dispositivo privilegiado de la máquina de la argentinidad, nos devuelve [...] a nuestro destino de siempre: que no existen logros sin ruina, que los sueños nos nacen frustrados, que el conflicto es el motor de nuestra existencia, que el fracaso nos enamora. Maradona en el '78 (desafectado), Maradona en el '82 (expulsado), Maradona en el '90 (derrotado), Maradona en el '94 (suspendido) completan y complementan al Maradona victorioso de 1986.

Maradona nos da sentido, por eso nos tiene hartos (Kohan 2008).

Ahí estaría la clave, la síntesis posible del deseo y la realidad, la postura necesaria (difícil de adoptar, por lo visto) para asumir la realidad de un país que vivió la grandeza y el fracaso. El sentido estaría ahí, precisamente, en los mitos desmitificados que integran belleza y debilidad, pasión y desilusión. Buscar el sentido de la argentinidad tendría como condición previa, en fin, la aceptación de la paradoja, de una fragilidad de lo homogéneo, tarea cuya dificultad - o más bien fracaso - no cesa de expresarse, de manera vigorosa y lograda, en la obra de Martín Kohan.

\section{Bibliografía}

Bachelard, Gaston, 2010, L'eau et les rêves, Paris, José Corti.

Friera, Silvina, 2005, «Prefiero recuperar las antinomias», Página/12, mayo de 2005.

Genette, Gérard, 1972, Figures III, Paris, Seuil.

Kohan, Martín, 1993, La pérdida de Laura, Buenos Aires, Tantalia.

Kohan, Martín, 1997, El informe. San Martín y el otro cruce de los Andes, Buenos Aires, Editorial Sudamericana.

Kohan, Martín, 2005, Segundos afuera, Buenos Aires, Editorial Sudamericana.

Kohan, Martín, 2010, Cuentas pendientes, Buenos Aires, Anagrama.

Kohan Martín, 2008, «Argentinismos. El nuevo gran DT», Perfil, nov. de 2008.

Kohan, Martín, 2009, «La muerte de un escritor», Perfil, julio de 2009.

Pons, María Cristina, et Soria, Claudia (ss dir.), 2005, Delirios de grandeza. Los mitos argentinos: memoria, identidad, cultura, Rosario, Beatriz Viterbo. 